\title{
Article \\ Calcium Carbonate Particles Filled Homopolymer Polypropylene at Different Loading Levels: Mechanical Properties Characterization and Materials Failure Analysis
}

\author{
Yucheng Peng *, Munkaila Musah (D, Brian Via and Xueqi Wang \\ School of Forestry and Wildlife Sciences, Auburn University, 602 Duncan Drive, Auburn, AL 36849, USA; \\ mzm0263@auburn.edu (M.M.); Brianvia@auburn.edu (B.V.); xzw0077@auburn.edu (X.W.) \\ * Correspondence: yzp0027@auburn.edu
}

\section{check for} updates

Citation: Peng, Y.; Musah, M.; Via, B.; Wang, X. Calcium Carbonate Particles Filled Homopolymer Polypropylene at Different Loading Levels:

Mechanical Properties

Characterization and Materials Failure Analysis. J. Compos. Sci. 2021, 5, 302. https://doi.org/10.3390/ jcs5110302

Academic Editor: Francesco Tornabene

Received: 19 October 2021 Accepted: 15 November 2021 Published: 18 November 2021

Publisher's Note: MDPI stays neutral with regard to jurisdictional claims in published maps and institutional affiliations.

Copyright: (C) 2021 by the authors. Licensee MDPI, Basel, Switzerland. This article is an open access article distributed under the terms and conditions of the Creative Commons Attribution (CC BY) license (https:// creativecommons.org/licenses/by/ $4.0 /)$.

\begin{abstract}
Calcium carbonate $\left(\mathrm{CaCO}_{3}\right)$ particles have been widely used in filling thermoplastics for different applications in automotive, packaging, and construction. No agreement has been reached in the research community regarding the function of $\mathrm{CaCO}_{3}$ for enhancing toughness of homopolymer polypropylene (HPP). This study was to understand the effect of different loading levels of $\mathrm{CaCO}_{3}$ on HPP toughness, including notched and unnotched impact strength. A batch mixer was used to thermally compound $\mathrm{CaCO}_{3}$ particles with HPP at loading levels of 10, 20, 30, 40, and $50 \mathrm{wt} . \%$, followed by specimen preparation using an injection molding process. The mechanical properties of the composites, including tensile, flexural, and impact were characterized. The results indicated that tensile strengths decreased significantly with increasing loading levels of $\mathrm{CaCO}_{3}$ particles while the tensile and flexural modulus increased significantly with increasing particle loadings. The composite tensile properties changed linearly with increasing $\mathrm{CaCO}_{3}$ loadings. The notched Izod impact strength of the composites was sustained by adding $\mathrm{CaCO}_{3}$ particles up to $40 \mathrm{wt}$.\% while the unnotched impact strength decreased significantly with the addition of $\mathrm{CaCO}_{3}$ particles. Different deformation mechanisms between notched (fracture propagation) and unnotched (fracture initiation and propagation) impact tests were proposed to be the reason.
\end{abstract}

Keywords: homopolymer polypropylene; calcium carbonate; composites; impact strength

\section{Introduction}

Tailoring the mechanical properties of homopolymer polypropylene (HPP) for use in packaging, construction, and automotive industries continues to attract considerable attention [1-17]. The structural applications of HPP as an engineering thermoplastic are limited, due to their low impact resistance, especially at room and low temperature ranges $[1,4,9,10]$. HPP has shown potential of enhanced impact resistance upon inclusion of various types of fillers. Four main types of fillers have been researched extensively to improve the impact strength of HPP: rigid organic particle (wood fiber) filled PP, rigid inorganic particle (clay) filled PP, rubber blended PP, and the combination of rigid organic and inorganic particles filled PP $[4,6,9,10,12,15,17]$. Among the different filler categories, rigid inorganic particle filled PP showed several advantages, including raw material low cost, improved Young's modulus, easy processing operation in commercial settings, etc. This study was to understand the mechanical behaviors of HPP filled by rigid inorganic particles at a variety of loading levels, focusing on the toughness change of filled HPP with different loadings of rigid inorganic particles.

According to the rule of mixtures, adding brittle inorganic filler particles in HPP would increase the composite modulus and decrease the toughness, i.e., impact resistance [18]. Some studies in the literatures have shown the embrittling effect of rigid inorganic fillers in polymer systems $[1,19,20]$. An increase in loading levels of fillers also reduces the impact 
resistance of the polymer system due to the reduced energy absorption capability of the matrix polymer. However, other research studies have shown increased modulus and impact resistance at the same time by adding rigid inorganic filler in polymer systems [1,18,21-23]. A heterogeneous system is formed by adding rigid inorganic particles in HPP with a threedimensional interphase formed around the surface of inorganic fillers. The interphase has different structures and behaves differently than the bulk polymer matrix material due to the effect of inorganic particles [24,25]. With different loading levels of particles in the system, the volume of interphase in the composite varies, resulting in different portions of bulk polymer matrix material and different mechanical behaviors of the manufactured composites. Under external stress, the interfacial debonding mechanism and composite failure models would be expected to differ than that of a pure polymer matrix.

Mechanical behaviors of rigid inorganic particles filled polymer systems have been researched by many groups, especially for the system capable of increasing toughness of polymers $[1,3,9,14,15,17,19,23,26-30]$. The previous research indicated that the main mechanisms of toughening semi-crystalline polymer such as HPP with rigid inorganic particles incorporation involve a series of mechanical deformations, starting with stress concentration, followed by debonding of polymer/particle interface, and lastly through shear yielding of polymer matrix phase between inorganic particles $[1,15,17]$. Stress concentration induced debonding between polymer and particle interface was believed to be the initial plastic deformation mechanism causing the failure of the heterogeneous system [31]. This is particularly true for the PP composite system due to its low polarity and low surface energy characters compared with the polar nature of most inorganic particles $[1,9,15,19,29]$.

When external forces are applied to rigid inorganic particles filled polymer composites, rigid particles act as stress concentrators in the matrix during deformation due to differences in moduli of polymer and rigid particles. Without strong chemical bonding between particles and polymer matrix, voids start to form between the two phases as force increases. Further increase in the external force would result in enlargement of voids through coalescence and further plastic deformation of polymer matrix phase, causing shear yielding of the matrix material [15]. At this moment, the system has the ability to absorb larger quantities of energy upon fracture, increasing toughness. A polymer must possess a high yield stress and can be yielded in the bulk phase to sustain the high toughness of the system. From the literature, additional requirements need to be fulfilled for rigid inorganic particles to function as a toughening agent in this mechanical deformation process [15,27]. These requirements have been summarized as homogeneous dispersion of particles in a polymer matrix with particle sizes less than five micrometers $(\mu \mathrm{m})$ and particle aspect ratios close to one. With inorganic particles in the nanometers range, significant improvement in impact resistance has been demonstrated by different research groups [32,33]. The tensile moduli of the composites have also been synergistically improved.

Toughening HPP using rigid inorganic particles needs to be practiced carefully and certain requirements must be met, i.e., the particle sizes are less than five micrometers. However, a complete story of the mechanical behaviors of rigid inorganic particles filled HPP has not been unraveled, such as the effect of adding rigid inorganic particles on unnotched impact strength and the maximum loading level of particles to be added to achieve the toughening effect. The other challenge is whether we need to specifically prepare the rigid inorganic particles with sizes less than five micrometers. The objective of this study was to understand the effect of rigid inorganic particles, a commercial grade of calcium carbonate $\left(\mathrm{CaCO}_{3}\right)$ particles in this specific case, at different loading levels on mechanical behaviors of HPP. The research results indicated that inclusion of $\mathrm{CaCO}_{3}$ particles without any specific preparations significantly impacted the mechanical properties of HPP. A linear relationship was observed for the tensile properties change, including modulus, strength, and elongation at yield, with the loading levels of $\mathrm{CaCO}_{3}$ in the HPP matrix. A mechanism explaining this linear relationship was proposed. The notched Izod impact strength of $\mathrm{CaCO}_{3}$ filled HPP maintained at the same level with that of HPP as the particle loading levels are up to $40 \mathrm{wt} . \%$. Unnotched Izod impact strength, however, 
decreased significantly with the lowest loading $\mathrm{CaCO}_{3}$ particles of $10 \mathrm{wt} . \%$. The different mechanisms leading to the different changes of notched and unnotched impact strengths were discussed.

\section{Materials and Methods}

\subsection{Materials}

A commercial grade HPP with a density of $0.9 \mathrm{~g} / \mathrm{cm}^{3}$ and a melt flow rate of $20 \mathrm{~g} / 10 \mathrm{~min}$ at $230{ }^{\circ} \mathrm{C} / 2.16 \mathrm{~kg}$ was obtained to be used as the matrix material. A commercial grade of precipitated $\mathrm{CaCO}_{3}$ particles used in this study was procured from Research Product International (Radnor, PA, USA). The $\mathrm{CaCO}_{3}$ particle was delivered in a sealed plastic container with a moisture content less than $2 \mathrm{wt} . \%$ and the particles were stored in the sealed container to avoid absorption of moisture after each use.

\subsection{Specimen Preparations}

Thermal compounding of $\mathrm{CaCO}_{3}$ particles with HPP was performed using a C.W. Brabender mixer (CWB-2128, Hackensack, NJ, USA) at $205^{\circ} \mathrm{C}$. The two roller blades of the mixer, simulating the twin-screw extruder mixing action, counter-rotated at $60 \mathrm{rpm}$. The loading levels of $\mathrm{CaCO}_{3}$ used in this study were 10, 20,30,40, and $50 \mathrm{wt}$ \% based on the weight of composites (weight of $\mathrm{CaCO}_{3}$ plus weight of HPP). The HPP pellets were first melted in the mixer at $205^{\circ} \mathrm{C}$ for $8 \mathrm{~min}$ and then $\mathrm{CaCO}_{3}$ particles were added for mixing for another $5 \mathrm{~min}$. After the thermal compounding, the mixtures were ground into pellets using a low-speed granulator (Shini Plastic Technologies Inc., Willoughby, $\mathrm{OH}$, USA) with a sieve size of $3 \mathrm{~mm}$. The mixture pellets were then dried and injection molded into testing specimens according to the ASTM D638 (Type I), ASTM D790, and ASTM D256 using a benchtop injection molding machine (Medium Machinery, LLC., Woodbridge, VA, USA). The injection molding temperature was set up at $195^{\circ} \mathrm{C}$ with an injection pressure of around $90 \mathrm{MPa}$. Virgin HPP was also mixed using the same process and then the mixed HPP specimens were injection molded for mechanical tests as a control.

\subsection{Mechanical Property Tests}

Tensile, flexural, and impact tests of $\mathrm{CaCO}_{3}$ filled HPP composites were performed according to ASTM D638, ASTM D790, and ASTM D256. Tests were conducted in an environmentally conditioned room at $23 \pm 2{ }^{\circ} \mathrm{C}$ and $50 \pm 5 \%$ relative humidity (RH). Tensile tests were performed using a Zwick-Roell universal testing machine (Kennesaw, GA, USA) with 10,000-N load cell. An Epsilon axial extensometer SN87275 (Jackson, WY, USA) was used to measure the strain during the tensile test. The speed of testing was $5 \mathrm{~mm} / \mathrm{min}$ and the strain rate at the start of test is $0.1 \mathrm{~min}^{-1}$. The tensile strength, percent elongation at yield and modulus of elasticity (MOE) were obtained. Flexural tests were conducted with a 500-N load cell attached to a Mark-10 ESM750s (Copiague, NY, USA) flexural testing fixture. Flexural tests were carried out using both procedures A and B specified in ASTM D790 and the outer fiber strain rates for procedures A and B are 0.01 and $0.1 \mathrm{~min}^{-1}$, respectively. Under the two strain rates, the specimens did not yield or break and the flexural properties, including flexural strength and MOE, were reported at 5\% strain using procedure B. Izod impact testing specimens were prepared using a manual CEAST notcher (Instron, Norwood, MA, USA) and impact tests were performed on notched and unnotched composites specimens using an XJUD Digital Charpy Izod Impact Testing Machine (Deli Group CO. Ltd., Ningbo, China). At least five replicates were tested for each composite formulation to determine the tensile and flexural properties and ten specimens were used to obtain the Izod impact strength. Mixed HPP specimens were tested using the same procedures. The average values for the mechanical properties of mixed HPP and $\mathrm{CaCO}_{3}$ filled HPP composites were reported. Statistical analysis of the mechanical properties was performed and a significance level of 0.05 was employed. 


\subsection{Melt Flow Rate (MFR) Measurement}

The MFR of the manufactured composites was determined using a Melt Flow Rate Tester (Techtongda, Markham, ON, Canada) according to the ASTM D1238 on pellet samples obtained from grinding of the mixture after mixing. The measurements were conducted at $230{ }^{\circ} \mathrm{C}$ with the weight of $2.16 \mathrm{~kg}$. Five replicates were measured for each sample and weighed to the nearest $1 \mathrm{mg}$. The standard melt flow rate number with the units of $\mathrm{g} / 10 \mathrm{~min}$ was reported.

\subsection{Scanning Electron Microscopy (SEM)}

The $\mathrm{CaCO}_{3}$ particles and the fracture surfaces of impact tested specimens were sputter coated with gold for $60 \mathrm{~s}$ in a Q150R ES sputter coating device acquired from Electron Microscopy Sciences (Hatfield, PA, USA). Before the sputter coating process, $\mathrm{CaCO}_{3}$ particles were deposited on conductive carbon tapes, trying to disperse each individual particle for better conductivity during SEM characterization. The calcium carbonate particles and the fracture surfaces were examined using a Zeiss Evo 50VP scanning electron microscope (Oberkochen, Germany) at $20 \mathrm{kV}$ voltage. The morphologies of calcium carbonate and the composite fracture surfaces were reported.

\section{Results and Discussion}

\subsection{Morphology of Calcium Carbonate Particles}

The morphologies of calcium carbonate particles were examined using SEM and the micrographs at different magnifications are shown in Figure 1. Irregular shape solid particles with aspect ratios around one or greater were observed. The majority of the particle sizes of $\mathrm{CaCO}_{3}$ particles ranged from less than one micrometer to around $10 \mu \mathrm{m}$. Large particles with the longest dimensions of around $25 \mu \mathrm{m}$ also exist. Sharp edges were also observed on most of the particles.
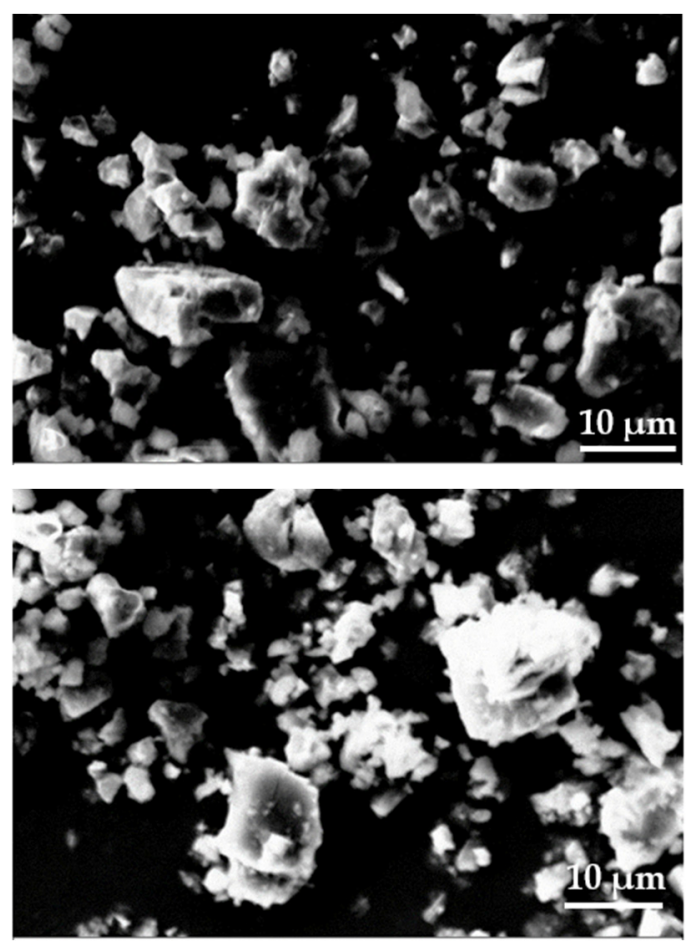

(a)
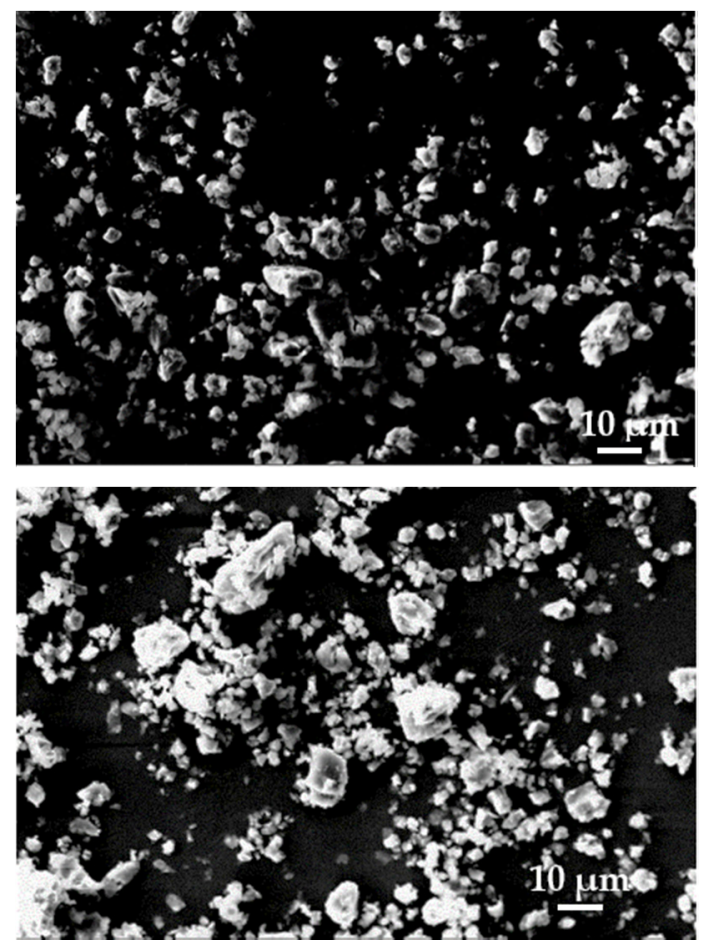

(b)

Figure 1. SEM micrographs of $\mathrm{CaCO}_{3}$ particles at different magnifications (a) $5000 \times$ and (b) $2000 \times$. 


\subsection{Tensile and Flexural Properties of $\mathrm{CaCO}_{3}$ Particles Filled HPP}

The tensile properties of mixed $\mathrm{HPP}$ and $\mathrm{CaCO}_{3}$ particles filled HPP were summarized, and the results are shown in Figure 2. The detailed numbers and statistical analysis results are shown in Table 1. Different letters of A, B, C, D, E, and F in Table 1 represent significant differences in the mechanical results. After the batch mixer processing, HPP has an MOE and tensile strength of $1.54 \mathrm{GPa}$ and $32.1 \mathrm{MPa}$, respectively (Figure $2 \mathrm{a}$ and Table 1). Addition of $\mathrm{CaCO}_{3}$ particles at loading levels of 10, 20, 30, 40, and $50 \mathrm{wt} . \%$ into HPP through the batch mixer increased the tensile MOE of the composites to 1.85, 2.02, 2.09, 2.70, and $2.99 \mathrm{GPa}$, which are $20,31,36,75$, and $94 \%$ higher than that of pure HPP, respectively. On the other side, tensile strengths significantly decreased from $32.1 \mathrm{MPa}$ to $30.4,29,26.1$, 23.3, and 20.4 MPa with inclusion of 10, 20, 30, 40, and 50 wt.\% $\mathrm{CaCO}_{3}$, representing decreases of $5,10,19,27$, and $36 \%$. The elongations at yield (strain) during the tensile testing were also characterized using an extensometer and the data is shown in Figure $2 b$ and Table 1. When compared with HPP, inclusion of $\mathrm{CaCO}_{3}$ at loading levels of 10, 20, 30, 40 , and $50 \mathrm{wt} . \%$ significantly decreased the strain at yield from $10.7 \%$ to $7.4,7.0,5.7,3.9$, and $2.6 \%$, which are around $31,35,46,64$, and $76 \%$ lower than that of pure HPP.

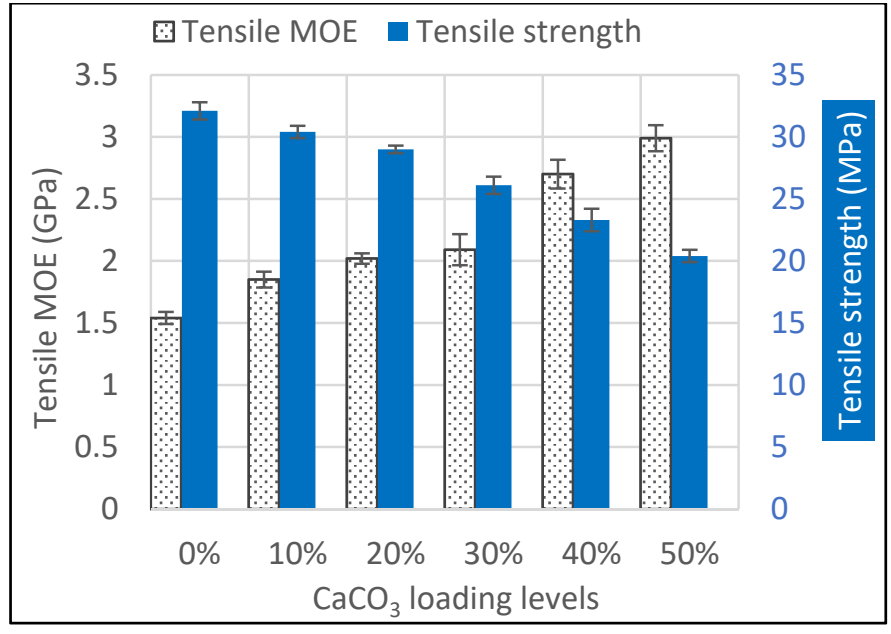

(a)

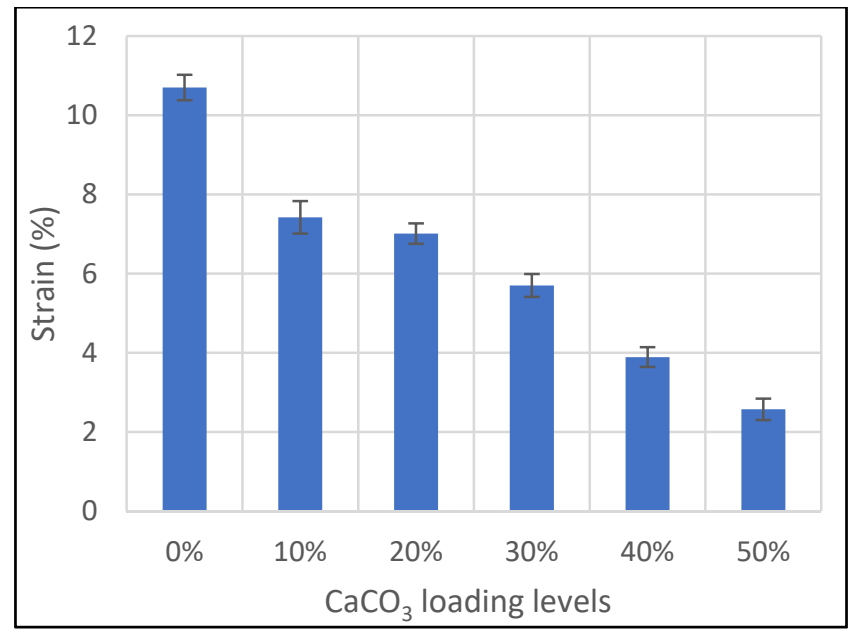

(b)

Figure 2. The tensile properties of the HPP and $\mathrm{CaCO}_{3}$ filled HPP composites (a) tensile modulus of elasticity (MOE) and strength and (b) tensile strain at yield.

Table 1. The mechanical properties of $\mathrm{CaCO}_{3}$ particles filled HPP.

\begin{tabular}{|c|c|c|c|c|c|c|c|c|c|c|c|c|c|c|}
\hline \multirow{3}{*}{$\begin{array}{c}\text { Composite } \\
\operatorname{HPP}(0 \%)\end{array}$} & \multicolumn{6}{|c|}{ Tensile Properties } & \multicolumn{4}{|c|}{ Flexural Properties } & \multicolumn{4}{|c|}{ Impact Strength $\left(\mathrm{kJ} / \mathrm{m}^{2}\right)$} \\
\hline & \multicolumn{2}{|c|}{ MOE (GPa) } & \multicolumn{2}{|c|}{ Strength (MPa) } & \multicolumn{2}{|c|}{ Strain (\%) } & \multicolumn{2}{|c|}{ MOE (GPa) } & \multicolumn{2}{|c|}{ Strength $(\mathrm{MPa})^{3}$} & \multicolumn{2}{|c|}{ Notched } & \multicolumn{2}{|c|}{ Unnotched } \\
\hline & $1.54 \pm 0.05^{1}$ & $E^{2}$ & $32.1 \pm 0.7$ & $\mathrm{~F}$ & $10.7 \pm 0.3$ & $\mathrm{~A}$ & $1.50 \pm 0.02$ & $\mathrm{E}$ & $50.0 \pm 0.3$ & $\mathrm{C}$ & $1.66 \pm 0.15$ & $\mathrm{~A} / \mathrm{B}$ & $50.3 \pm 8.3$ & A \\
\hline $10 \% \mathrm{CaCO}_{3}$ & $1.85 \pm 0.06$ & $\mathrm{D}$ & $30.4 \pm 0.5$ & $\mathrm{E}$ & $7.4 \pm 0.4$ & B & $1.98 \pm 0.08$ & $\mathrm{D}$ & $57.1 \pm 1.3$ & A & $1.62 \pm 0.12$ & B & $30.1 \pm 3.5$ & B \\
\hline $20 \% \mathrm{CaCO}_{3}$ & $2.02 \pm 0.04$ & $\mathrm{C}$ & $29.0 \pm 0.3$ & $\mathrm{D}$ & $7.0 \pm 0.3$ & B & $1.92 \pm 0.13$ & $\mathrm{D}$ & $53.3 \pm 2.0$ & B & $1.75 \pm 0.10$ & $\mathrm{~A} / \mathrm{B}$ & $24.5 \pm 4.6$ & $\mathrm{C}$ \\
\hline $30 \% \mathrm{CaCO}_{3}$ & $2.09 \pm 0.13$ & $\mathrm{C}$ & $26.1 \pm 0.7$ & $\mathrm{C}$ & $5.7 \pm 0.3$ & $\mathrm{C}$ & $2.37 \pm 0.08$ & $\mathrm{C}$ & $53.5 \pm 1.4$ & B & $1.81 \pm 0.14$ & A & $27.3 \pm 4.7$ & $\mathrm{~B} / \mathrm{C}$ \\
\hline $40 \% \mathrm{CaCO}_{3}$ & $2.70 \pm 0.12$ & B & $23.3 \pm 0.9$ & B & $3.9 \pm 0.3$ & D & $2.75 \pm 0.09$ & B & $49.5 \pm 1.1$ & C & $1.77 \pm 0.32$ & $\mathrm{~A} / \mathrm{B}$ & $20.1 \pm 3.5$ & $\mathrm{D}$ \\
\hline $50 \% \mathrm{CaCO}_{3}$ & $2.99 \pm 0.11$ & A & $20.4 \pm 0.5$ & A & $2.6 \pm 0.3$ & $\mathrm{E}$ & $3.26 \pm 0.37$ & A & $43.7 \pm 3.3$ & $\mathrm{D}$ & $1.33 \pm 0.15$ & C & $5.67 \pm 0.5$ & $\mathrm{E}$ \\
\hline
\end{tabular}

${ }^{1}$ Standard deviation. ${ }^{2}$ The letters A, B, C, D, E, and F represent the significant levels in statistical analysis. The values with different letters are significantly different. ${ }^{3}$ The strength for flexural properties is the stress at $5 \%$ strain since no specimens broke.

After injection molding, dispersed $\mathrm{CaCO}_{3}$ particles were packed with $\mathrm{HPP}$ under high pressure in an aluminum mold followed by cooling. When the specimens were cooled to a lower temperature, specimen shrinkage in all the dimensions occurred in the mold and less shrinkage was observed for the $\mathrm{CaCO}_{3}$ particles filled HPP specimens than that of pure HPP specimens. During specimen cooling, $\mathrm{CaCO}_{3}$ particles in the composites restricted the movement of molecular chains of HPP, decreasing the shrinkage. Simultaneously, the particles also interrupted the crystallization process the composites went through during cooling and the mechanical behaviors of $\mathrm{CaCO}_{3}$ particles filled HPP would therefore change. After settling the specimens for a period at room conditions, the polymer phase 


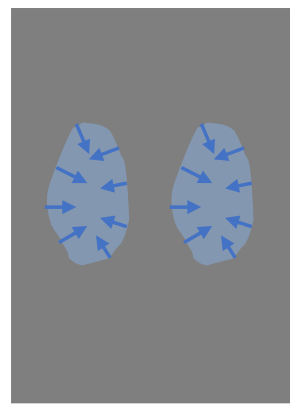

(a)

approached an equilibrium without any further deformation and polymer crystallization completed. HPP has a glass transition temperature lower than room temperature and polymer molecular chains can still move without significant effect on material properties. Under this approximate equilibrium, residual stress could be existed on the $\mathrm{CaCO}_{3}$ particle which is applied by polymer molecules due to polymer shrinkage during cooling. Therefore, $\mathrm{CaCO}_{3}$ particles existed in the composite system bearing residual compression stresses with a small strain because of a high MOE (Figure 3a). All the compression stresses are normal to the particle surface at all points.

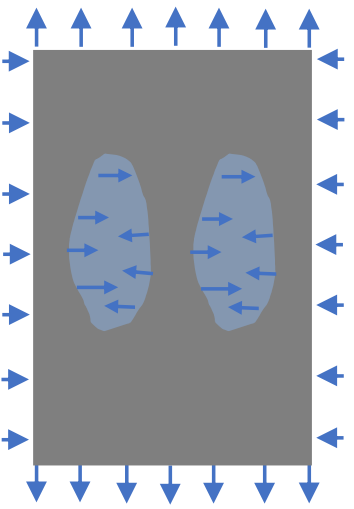

(b)

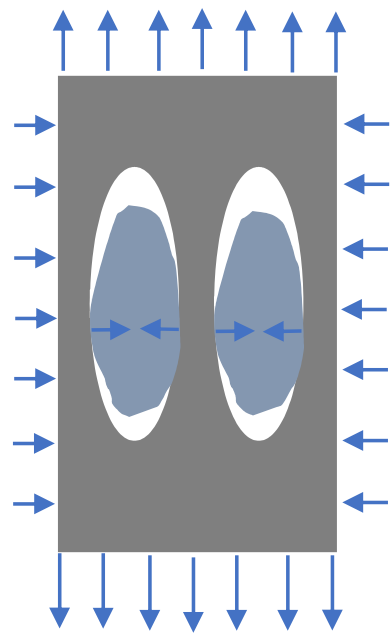

(c)

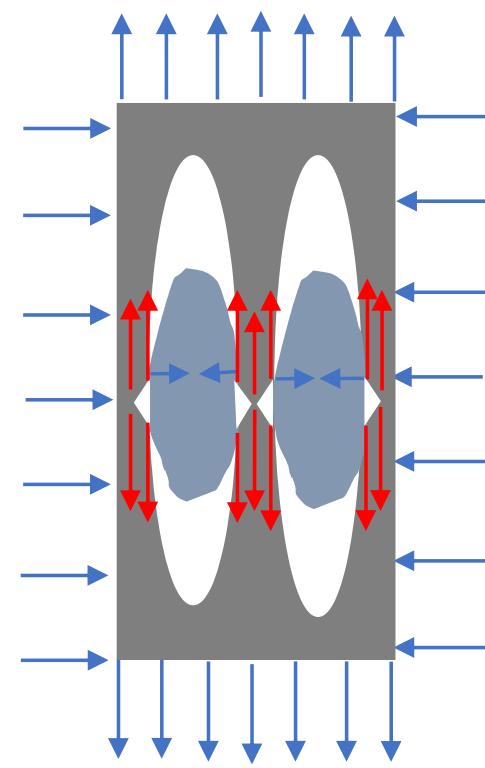

(d)

Figure 3. Schematic representation of the $\mathrm{CaCO}_{3}$ fille HPP composites at equilibrium and under tensile load: (a) residual stress in $\mathrm{CaCO}_{3}$ particles, (b) initial stage of elastic deformation zone, (c) the end point of the elastic deformation zone, and (d) the yielding point of the composites.

Under tensile load for the equilibrated composite system, specimens of HPP and $\mathrm{CaCO}_{3}$ particle filled HPP responded with an initial deformation in the elastic region. In this initial phase of the elastic deformation zone, stress inside the whole specimen is uniform and initial uniform strain is generated in a very small magnitude according to the classical mechanics. In this stage, external load released the residual stress applied on $\mathrm{CaCO}_{3}$ particles along the tensile load direction, returning the particle to the zero-stress status and cancelling the strain in the tensile load direction which was caused by the initial residual stress (Figure 3b). Additionally, tensile load also applies shrinking force perpendicular to the tensile load direction on the specimen due to Poisson's ratio effect, compressing the $\mathrm{CaCO}_{3}$ particles cross the tensile load direction, simultaneously.

As the external tensile load increases the elastic strain of polymer phase would be much larger than that of $\mathrm{CaCO}_{3}$ particle because $\mathrm{MOE}$ of $\mathrm{CaCO}_{3}$ particle is much greater than that of HPP. With the same grip separation in this strain range, the deformation of $\mathrm{CaCO}_{3}$ particles cannot catch up with the deformation of HPP. Starting at this moment, polymer phase begins to separate with $\mathrm{CaCO}_{3}$ particles and debonding at a point of the interface occurs first along the tensile load direction. For an irregular shape rigid particle embedded in the polymer matrix, the farthest point on the particle surface in the tensile load direction debonds first, forming a void, and then the debonding slowly spreads along the particle surface to all directions. The debonding continues until voids form at all the interface perpendicular to the tensile load direction (Figure 3c). At the same time, as the specimen elongates in the direction of load, shrinkage continues to occur in the direction perpendicular to the load. Therefore, the polymer matrix would hold the rigid particle at 
the widest point and applies compression stresses on the particle (Figure 3c). This is the second stage deformation of the composite under tensile load. During this process, $\mathrm{CaCO}_{3}$ particles interfere with the mechanical responses of the composites under tensile stress and the dominant deformation mechanism is still in the elastic range, mostly occurring with the polymer phase. The tensile MOE characterization results shown in Figure 1 and Table 1 demonstrated the interferences from $\mathrm{CaCO}_{3}$ particles and tensile MOE increased with the interferences. When the loading levels of particles increased from 10 to $50 \mathrm{wt} \%$, more surface area of $\mathrm{CaCO}_{3}$ particles became involved in this interference, resulting in greater tensile MOE of the composites. At this second stage of elastic deformation, a shear force could also be generated on the particle if the widest dimension of the particle is not aligned with the transverse direction of the specimen, rotating the $\mathrm{CaCO}_{3}$ particles in the matrix during the deformation process.

These phenomena of elastic deformation of the specimen can also be indicated by the stress-strain curves of the tested specimen and a representative stress-strain curves for each sample is shown in Figure 4. In this elastic deformation range, higher loading $\mathrm{CaCO}_{3}$ particles in the composite needed a proportionally higher stress to reach the same strain assuming a similar uniform dispersion of these particles in HPP. Simultaneously, higher loading particle composites also required greater stresses to reach the initial phase of the elastic deformation zone (Figure 3b). A linear regression analysis on the tensile MOE (Y) versus $\mathrm{CaCO}_{3}$ loading levels $(X)$ showed a linear relation below:

$$
\mathrm{Y}=0.28 \mathrm{X}+1.21\left(\mathrm{R}^{2}=0.94\right)
$$

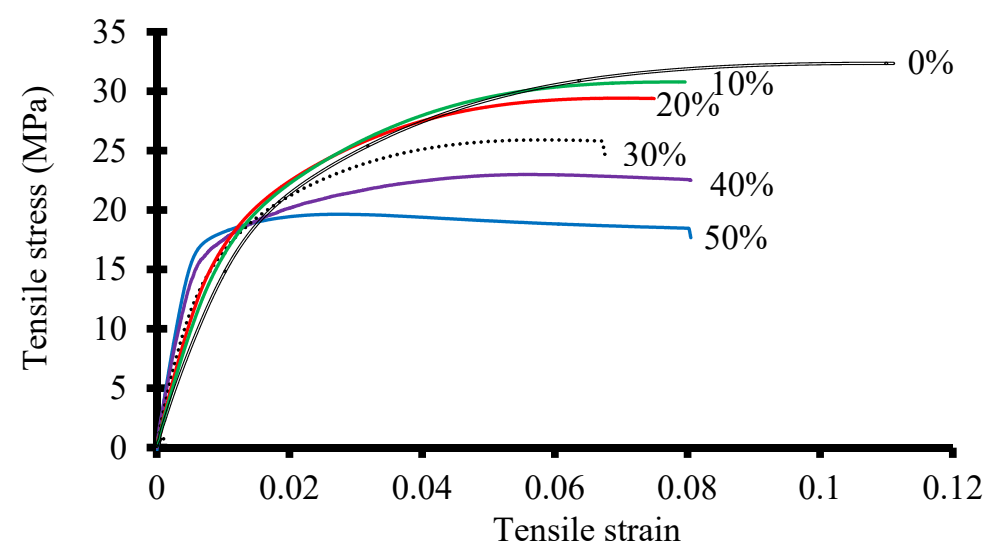

Figure 4. A set of representative stress-strain curves for the composites.

In this relationship, tensile MOE increased linearly with particle loading level, which verified the theory proposed above.

As a greater external tensile load continues to be applied to the testing specimen, plastic deformation of the HPP system dominates the deformation process with increased strain and the composite deformation passed the elastic zone. Rigid $\mathrm{CaCO}_{3}$ particles do not go through the plastic deformation in this case. At this stage, the slopes of the stress-strain curves start to decrease until the yield point of the composites is reached (Figure 4). At the point of composite yielding, rupture of the plastic matrix occurs, and tensile strength is obtained. During the plastic deformation range, additional tension stress is applied to the polymer phase in the transverse direction of the specimen by the $\mathrm{CaCO}_{3}$ particles. This tension stress is the reaction stress to the stress applied the $\mathrm{CaCO}_{3}$ particles. Therefore, the yielding and rupture of the polymer phase is achieved by the combination of the external tension load and the reaction tension stress from $\mathrm{CaCO}_{3}$ particles (Figure 3d). Sharp edges of $\mathrm{CaCO}_{3}$ also play a role in yielding the composite under tensile load.

At the yielding point, the tensile stress (strength) is calculated by dividing the external force with the cross-section area of the specimen and the force is only loaded to the polymer phase since there is a complete separation between polymer phase and $\mathrm{CaCO}_{3}$ particles in 
the loading direction. For the same cross-section area with the same amount of polymer phase, the tensile strength would be the same. When the loading levels of $\mathrm{CaCO}_{3}$ in the composites increased from 10 to $50 \mathrm{wt} . \%$, the amount of polymer phase in the cross-section decreased with a proportional rate and the tensile strength would decrease linearly with $\mathrm{CaCO}_{3}$ particle loading levels. The experimental results of the tensile strength are shown in Figure 1a and Table 1. Data analysis of the tensile strength showed a linear relationship between the tensile strength $(\mathrm{Y})$ and the $\mathrm{CaCO}_{3}$ particle loading level $(\mathrm{X})$ :

$$
Y=-2.36 X+35\left(R^{2}=0.98\right)
$$

Other factors, such as particle distribution and dispersion and the reaction tension stress applied by particles had a minor effect on tensile strength.

The tensile strain at yield behaved the same as the tensile strength (Figure 1b) and it decreased significantly with increasing $\mathrm{CaCO}_{3}$ particle loading levels. Along the tensile load direction, portion of polymer molecular chains was replaced by the $\mathrm{CaCO}_{3}$ particles, and the strain needed to achieve the tensile strength would decrease proportionally. The linear relationship between the strain at yield $(\mathrm{Y})$ and $\mathrm{CaCO}_{3}$ particle loading level $(\mathrm{X})$ is shown below.

$$
\mathrm{Y}=-1.50 \mathrm{X}+11.5\left(\mathrm{R}^{2}=0.96\right)
$$

In summary, the tensile properties of $\mathrm{CaCO}_{3}$ particles filled HPP changed linearly with particle loading levels. In our proposed explanation, the particle morphologies, including shape and size, and quantity play critical role affecting the tensile behaviors of the composites.

The flexural properties of pure HPP and $\mathrm{CaCO}_{3}$ particles filled HPP, including flexural MOE and strength, are shown Figure 5. Table 1 shows the detail numbers and the statistical analysis results. During the flexural tests, all the specimens did not yield or break at $5 \%$ strain limit at two different testing speeds. The flexural strength at $5 \%$ strain obtained using the rate of straining of the outer fiber of $0.1 \mathrm{~mm} / \mathrm{mm} / \mathrm{min}$ was reported in this study. The flexural MOE and strength of $\mathrm{HPP}$ are $1.50 \mathrm{GPa}$ and $50.6 \mathrm{MPa}$. Adding $\mathrm{CaCO}_{3}$ particles into HPP significantly increased the flexural MOE and the MOE at 10, 20, 30, 40 , and $50 \mathrm{wt} . \%$ particle loadings are 1.98, 1.92, 2.37, 2.74, and $3.26 \mathrm{GPa}$, which are 32, $28,58,83$, and $117 \%$ greater than that of pure HPP, respectively. The increase of flexural MOE is common when including rigid particles in polymer composites [34]. The flexural strength of the composites increased from 50.6 MPa for pure HPP by inclusion of the $\mathrm{CaCO}_{3}$ particles at 10, 20, and $30 \mathrm{wt} . \%$ and the flexural strengths are 57.1, 53.2, and 53.5, respectively. There is no significant difference on flexural strength for the composite with $40 \mathrm{wt} . \% \mathrm{CaCO}_{3}$ particles when compared with HPP. Adding $50 \mathrm{wt} . \% \mathrm{CaCO}_{3}$ significantly decreased the flexural strength of HPP. The deformation of the specimen during flexural test is complex, combining the tension on the bottom surface of the specimen and the compression at the top surface. In the particle loading level ranges of 10, 20, and $30 \mathrm{wt} . \%$, the compression strength is increased on top surface. Simultaneously, the stress needed for the bottom surface to reach $5 \%$ strain is increased, resulting in the increase of flexural strength of the composites. At the 40 and $50 \mathrm{wt} . \% \mathrm{CaCO}_{3}$ loadings, a larger portion of the composites surface contained interfaces between $\mathrm{CaCO}_{3}$ particle and polymer phase and a lower stress was required to achieve a $5 \%$ strain on the bottom surface than that needed in composites having 10-30 wt.\% particles, resulting in a lower flexural strength. At the $50 \mathrm{wt}$ \% loading level, the flexural strength is also lower than that of HPP (Figure 5). 


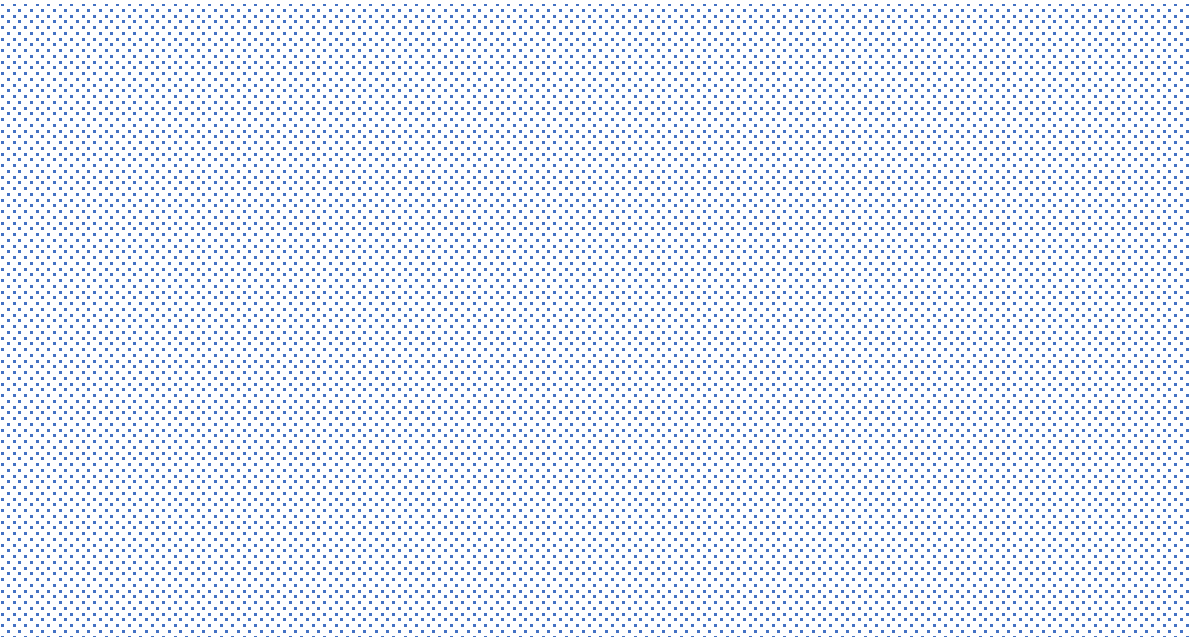

Figure 5. The flexural properties of the HPP and $\mathrm{CaCO}_{3}$ filled HPP composites.

\subsection{Impact Properties of $\mathrm{CaCO}_{3}$ Particles Filled HPP}

The Izod impact strengths tested notched and unnotched for all the composites are shown in Table 1 and Figure 6. The unnotched specimens were tested with the v-notch faced backward to the hammer load. The notched and unnotched impact strengths for pure HPP are 1.66 and $50.3 \mathrm{~kJ} / \mathrm{m}^{2}$. For notched impact tests, the impact strengths for composites with $\mathrm{CaCO}_{3}$ particle loading levels of $10,20,30,40$, and $50 \mathrm{wt} . \%$ are $1.62,1.75,1.81,1.76$, and $1.32 \mathrm{~kJ} / \mathrm{m}^{2}$. The statistical analysis indicated that the impact strengths of composites with $\mathrm{CaCO}_{3}$ particle loading levels of $10,20,30$, and $40 \mathrm{wt} . \%$ are not significantly different than that of pure HPP (Table 1). At $50 \mathrm{wt} . \%$ loading, the notched impact strength $\left(1.32 \mathrm{~kJ} / \mathrm{m}^{2}\right)$ is significantly lower $(20 \%)$ than that of pure HPP $\left(1.66 \mathrm{~kJ} / \mathrm{m}^{2}\right)$. For unnotched impact tests, the composites containing the rigid particles have significantly much lower impact strengths and the impact strengths at 10, 20,30,40, and $50 \mathrm{wt} . \%$ loading levels are 30.1, $24.5,27.3,20.1$, and $5.67 \mathrm{~kJ} / \mathrm{m}^{2}$, which are $40,51,46,60$, and $89 \%$ lower than that of pure $\operatorname{HPP}\left(50.3 \mathrm{~kJ} / \mathrm{m}^{2}\right)$ (Table 1 and Figure 6$)$.

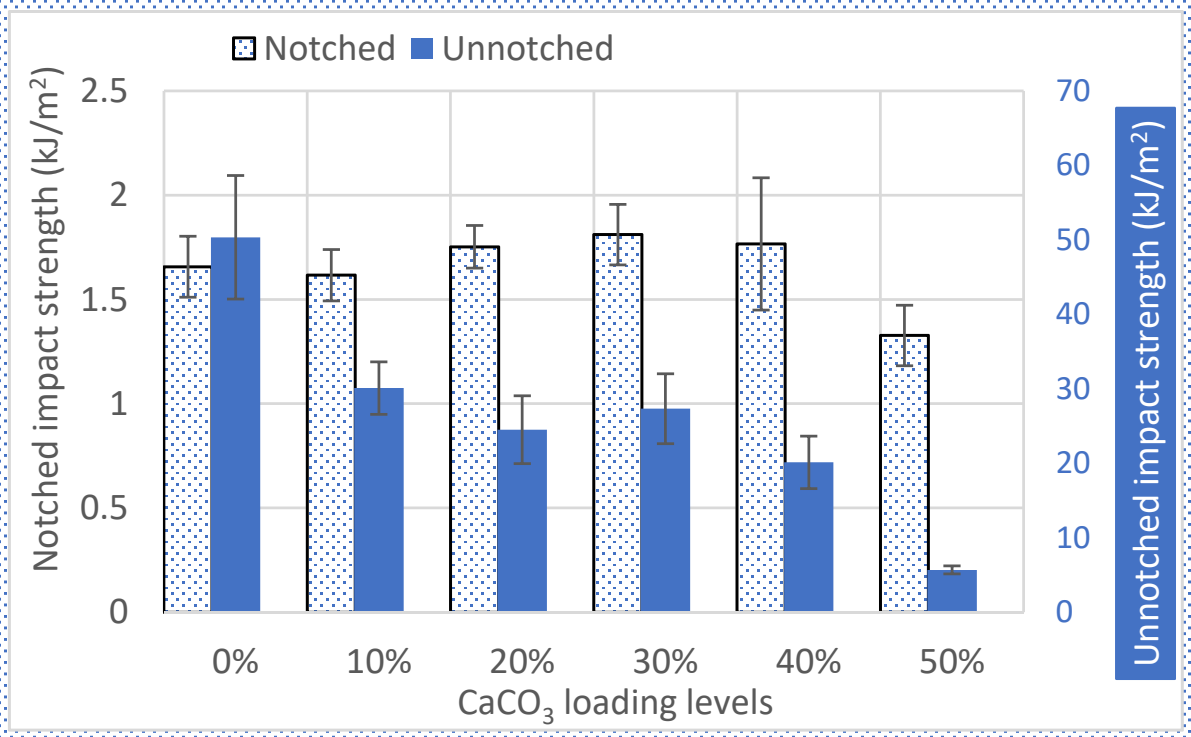

Figure 6. The impact strengths of $\mathrm{HPP}$ and $\mathrm{CaCO}_{3}$ filled $\mathrm{HPP}$ composites.

During the notched Izod impact test, the notching side of the specimen faced the impact load (Figure 7). The bottom half of the specimen was held tight by the specimen holder and compression forces were applied to the specimen during the test (Figure 7a). When the hammer contacted the specimen, a high magnitude of impact load applied strong 


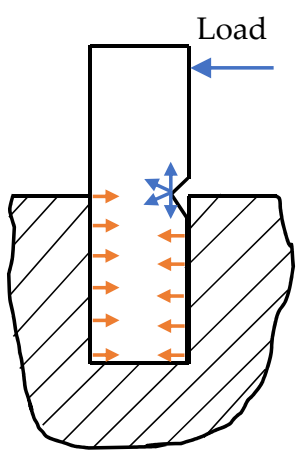

(a)

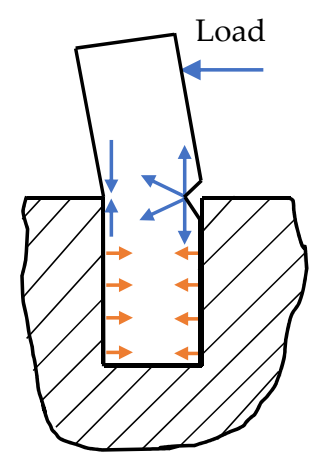

(b)

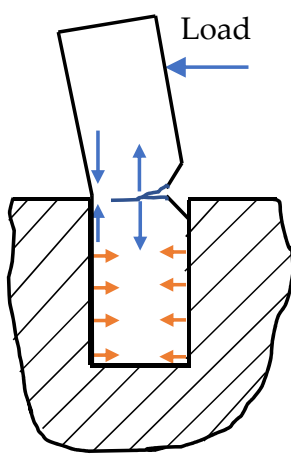

(c)

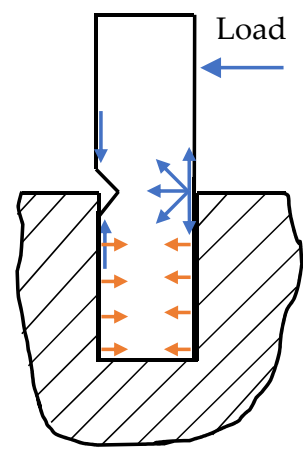

(d)

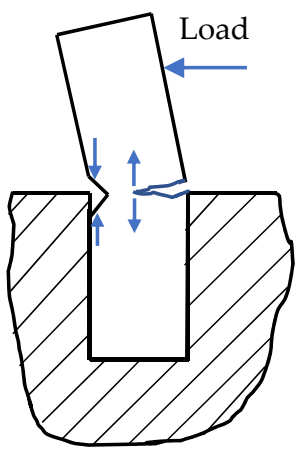

(e)

Figure 7. A schematic demonstration of specimen failure in notched Izod impact test (a-c) and unnotched Izod impact test $(\mathbf{d}, \mathbf{e})$.

In $\mathrm{CaCO}_{3}$ filled HPP composites, fracture can only occur in the polymer phase or at the interface between the particles and polymer. To be fractured, a polymer must go through elastic and plastic deformation zones. Assuming a same surface area $\left(\mathrm{A}_{\text {total }}\right)$ was created after specimen fracture for pure HPP and $\mathrm{CaCO}_{3}$ particles filled HPP composites, there would be less deformation energy for the polymer phase in $\mathrm{CaCO}_{3}$ particles filled HPP composites because partial fracture surface would be replaced with $\mathrm{CaCO}_{3}$ particle surface $\left(\mathrm{A}_{\text {filler }}\right)$. Under this circumstance, the energy for fracturing $\mathrm{CaCO}_{3}$ particles filled HPP composite would be lower and less amount of polymer has been fractured, resulting in lower impact resistance of the sample. The surface area for polymer fracture for $\mathrm{CaCO}_{3}$ filled HPP composite is $\left(A_{\text {total }}-A_{\text {filler }}\right)$. Another premise for the theory to be true is that much less energy is needed to separate $\mathrm{CaCO}_{3}$ particle and polymer matrix compared with fracture of polymer matrix. This is a reasonable estimation for this specific case because there was no chemical modification on the surface of $\mathrm{CaCO}_{3}$ particles. Alternatively, we can say that the work needed to separate unit interface of $\mathrm{CaCO}_{3}$ particle and polymer is lower than that for creating unit fracture surface of the polymer.

During the fracture propagation process, however, $\mathrm{CaCO}_{3}$ filled HPP behaved differently. The rigid particle functioned as a blocker for the fracture propagation. Therefore, the fracture front of the $\mathrm{CaCO}_{3}$ particles filled HPP followed a different path than pure HPP. The fracture front moved along the interface between $\mathrm{CaCO}_{3}$ particles and polymer matrix (Figure 8a), followed by fracturing the pure polymer phase between $\mathrm{CaCO}_{3}$ particles. With this new fracture path, a much larger fracture surface area $\left(\mathrm{A}_{\text {filler }}{ }^{\prime}>\mathrm{A}_{\text {filler }}\right)$ was created for $\mathrm{CaCO}_{3}$ particles filled HPP when compared with pure HPP. 


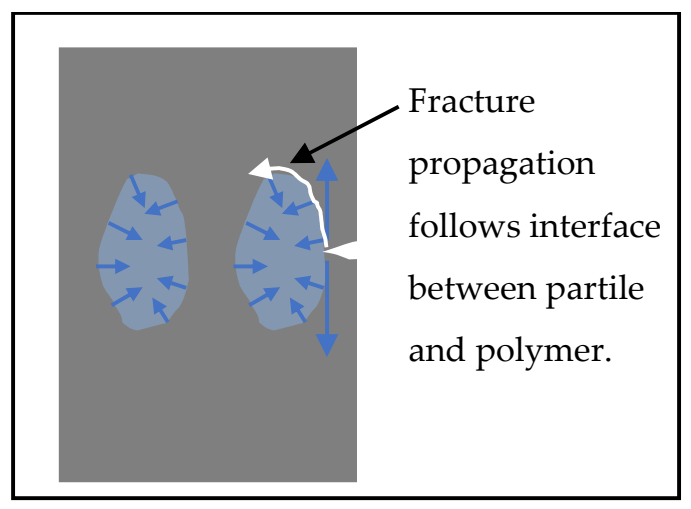

(a)

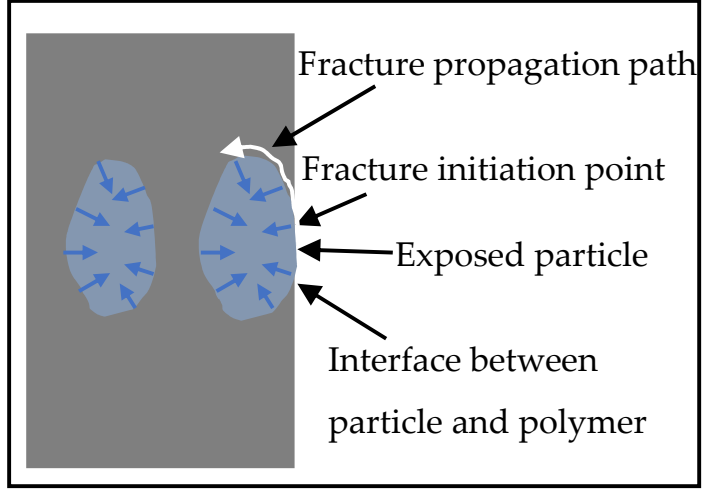

(b)

Figure 8. A schematic description of fracture propagation in notched Izod impact test (a) and fracture initiation in unnotched Izod impact test (b).

The different fracture surfaces can be demonstrated by the SEM micrograph observations (Figure 9) and much coarser fracture surfaces were observed for $\mathrm{CaCO}_{3}$ filled HPP samples. Simultaneously, separation between the particles and HPP can be easily identified (Figure 9) and this can verify that the work used to separate $\mathrm{CaCO}_{3}$ particle from HPP is lower than that to fracture HPP. In this case, the work used to create the new surface area of $\mathrm{A}_{\text {filler }}$ ' can compensate the work needed to create fracture polymer surface area of $\left(\mathrm{A}_{\text {total }}-\mathrm{A}_{\text {filler }}\right)$ and comparable impact strength can be achieved using $\mathrm{CaCO}_{3}$ fillers when compared with pure HPP (Figure 6 and Table 1). The phenomena of maintaining the notched Izod impact strength of HPP using up to $40 \mathrm{wt} . \% \mathrm{CaCO}_{3}$ particles are explained. At the $50 \mathrm{wt} . \% \mathrm{CaCO}_{3}$ particles loading level, a large portion of polymer was replaced by $\mathrm{CaCO}_{3}$ particles and the work for creating polymer fracture surface area of $\left(\mathrm{A}_{\text {total }}-\mathrm{A}_{\text {filler }}\right)$ cannot be made up by the work creating the new surface area of $\mathrm{A}_{\text {filler }}{ }^{\prime}$. The surface area of $\left(\mathrm{A}_{\text {total }}-\mathrm{A}_{\text {filler }}\right)$ is the polymer fracture surface area which has been replaced when $50 \mathrm{wt} . \% \mathrm{CACO}_{3}$ particles are included in the composite. Therefore, a lower Izod impact strength was observed at $50 \mathrm{wt} . \%$ loading level of $\mathrm{CaCO}_{3}$ particles. For the same composite, unnotched impact strengths are much higher than notched impact strengths. The fracture surfaces of specimens after unnotched impact tests were observed to be much rougher than those after notched impact tests. The fracture surfaces of HPP filled with 30 and $50 \mathrm{wt} . \%$ $\mathrm{CaCO}_{3}$ particles after the notched and unnotched impact tests are shown in Figure 10. The relatively rougher surface indicated that more surface was created during the unnotched impact test, and more energy was required for the same surface properties for the same composites. The greater energy led to higher impact strength which was calculated by dividing the energy using the specimen cross-section area. This is one reason unnotched impact strength is much greater than notched impact strength.

For unnotched Izod impact test, inclusion of $\mathrm{CaCO}_{3}$ particles significantly decreased the impact strength (Table 1 and Figure 6). The initial stresses the specimen encountered at the moment of contacting with impact hammer is shown in Figure $7 \mathrm{~d}$ and the fracture initiation started at the location contacting with the bottom sample holder. For composite with exposure of rigid particles on the surface, the fracture initiation point started at the interface between the rigid particle and the polymer phase due to a relatively weak bonding between the two incompatible surfaces (Figure 8 b). Under such circumstance, fracture initiated without yielding of polymer phase, resulting in a lower fracture initiation energy than that of pure polymer specimen. The fracture initiation energy needed for the system is another reason the unnotched impact strength is much greater than notched impact strength. Once the fracture has been initiated, propagation continued under the external impact load toward the notching tip of the specimen (Figure 7e). Fracture propagation in $\mathrm{CaCO}_{3}$ particles filled HPP behaved the same as that in notched impact test and created relatively larger fracture surface area. However, the fracture initiation in unnotched impact 
test probably required a much higher magnitude of energy than that in fracture propagation and dominated the fracture process. Therefore, the unnotched impact strength of $\mathrm{CaCO}_{3}$ particles filled HPP is much lower than that of pure HPP.

During the fracture propagation, less amount of polymer was fractured in the fracture propagation path for a composite with a higher loading level of $\mathrm{CaCO}_{3}$ particles and a lower impact strength was obtained. Simultaneously, a composite with a higher $\mathrm{CaCO}_{3}$ particle loading level has more exposed particles on the surface and less amount of polymer to be fractured in the fracture initiation phase, resulting in a lower impact strength.

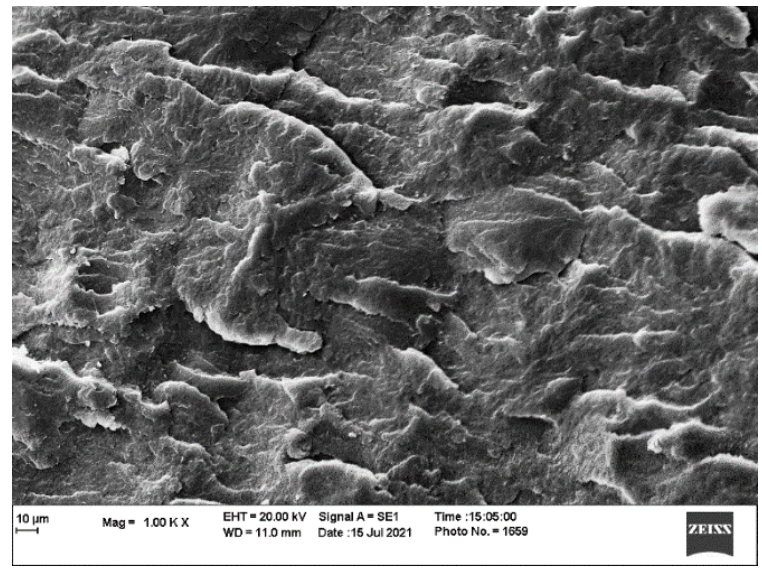

(a)

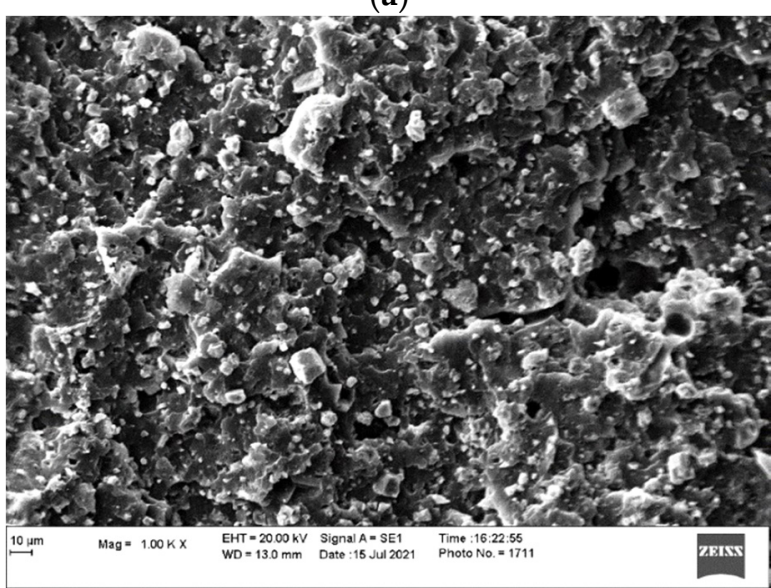

(c)

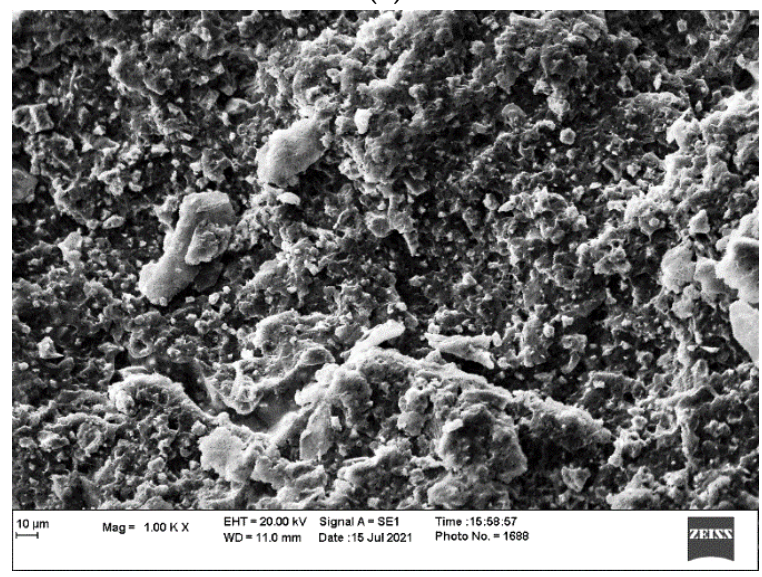

(e)

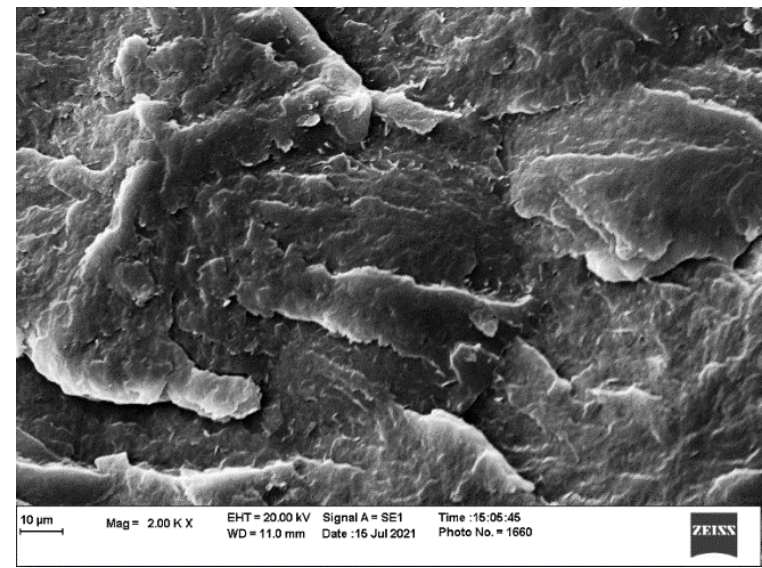

(b)

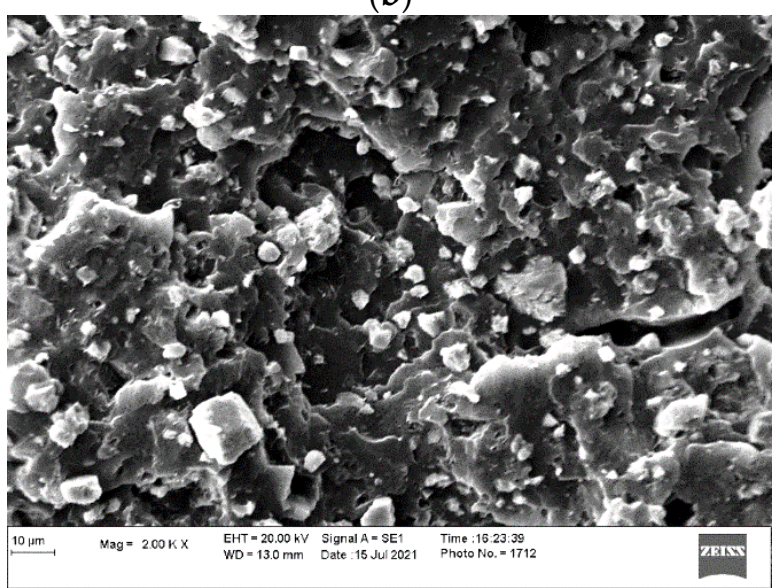

(d)

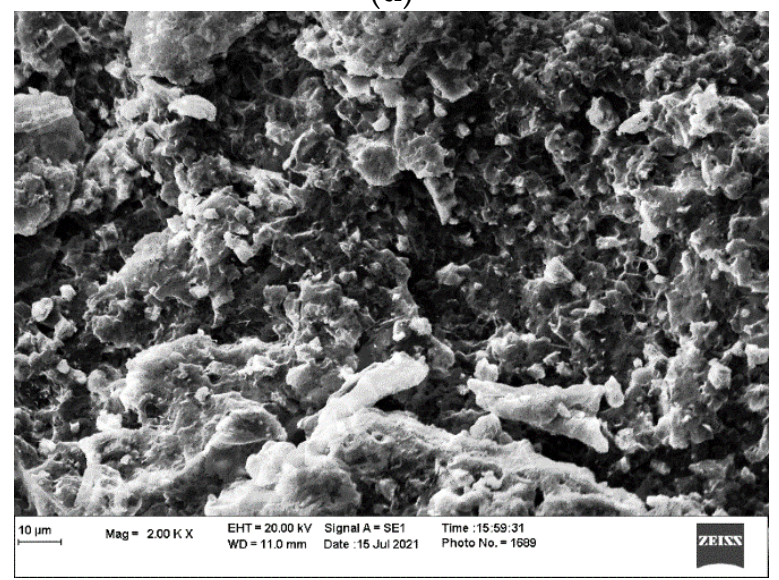

(f)

Figure 9. SEM micrographs of HPP: (a,b), 30 wt. $\% \mathrm{CaCO}_{3}$ filled HPP: (c,d), and 40 wt. $\% \mathrm{CaCO}_{3}$ filled $\mathrm{HPP}(\mathbf{e}, \mathbf{f})$. 


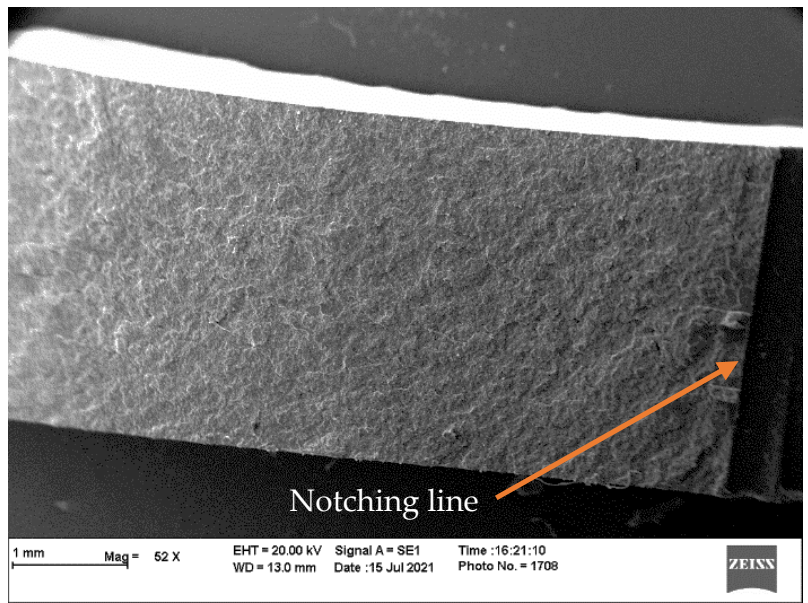

(a)

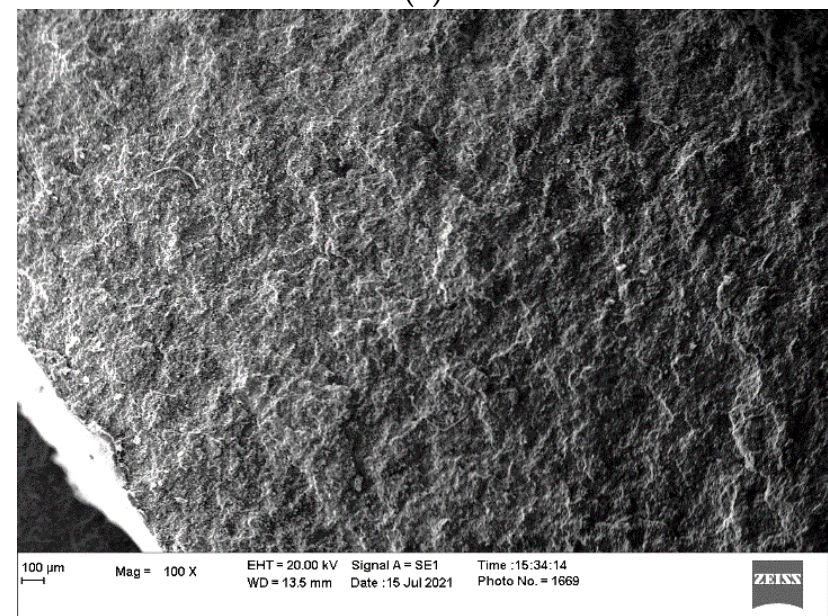

(c)

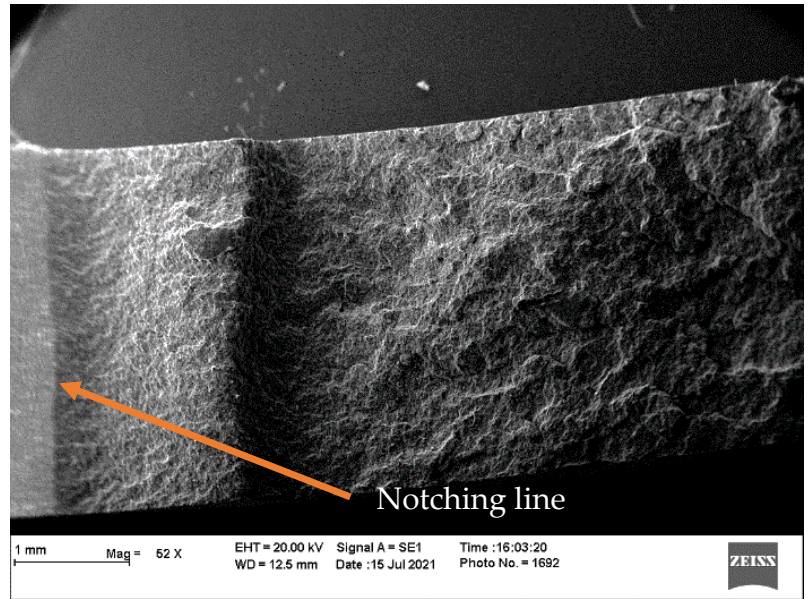

(b)

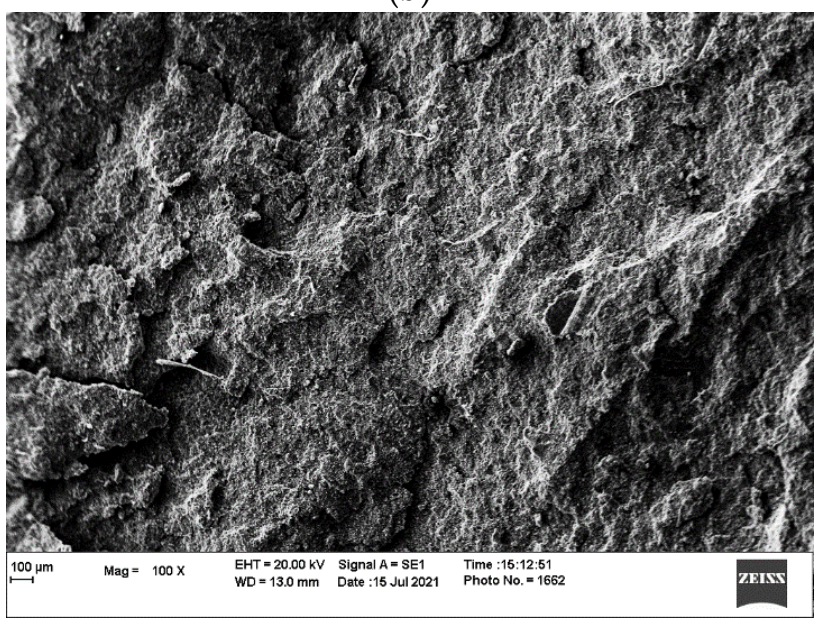

(d)

Figure 10. The comparison of the fracture surfaces for specimens after notched and unnotched impact tests: $(\mathbf{a}, \mathbf{b})$ notched and unnotched impact testing specimens for $\mathrm{HPP}$ filled with $30 \mathrm{wt} . \% \mathrm{CaCO}_{3},(\mathbf{c}, \mathbf{d})$ notched and unnotched impact testing specimens for HPP filled with $50 \mathrm{wt} \% \mathrm{CaCO}_{3}$.

\section{4. $M F R$}

The MFR data and their standard deviations of all the composites are shown in Figure 11. The statistical analysis results of MFR data are also shown in Figure 11. The MFR of HPP after mixing and grinding was $14.7 \mathrm{~g} / 10 \mathrm{~min}$. Adding $10 \mathrm{wt} \% \mathrm{CaCO}_{3}$ particles in the composites did not significantly change the MFR. With 20, 30, 40, and 50 wt.\% of $\mathrm{CaCO}_{3}$ particles, the MFRs of the composites decreased significantly to $13.2,12.0,10.5$, and $10.3 \mathrm{~g} / 10 \mathrm{~min}$, respectively. Generally, with rigid particles in polymer composites, the flow of the composites is limited by restricting the molecular motion $[35,36]$ and the MFR is lowered. At $10 \mathrm{wt}$ \% loading level, the number of particles is not enough to limit most of the polymer flow during the test and the polymer molecular motion still dominates the flow behavior of the composites. When the loading of $\mathrm{CaCO}_{3}$ particles increased from 10 to 20,30 , and $40 \mathrm{wt} . \%$, polymer molecules is resisted to move, and the resistance is in a linear relationship with $\mathrm{CaCO}_{3}$ particle loading. The linear relationship between the MFR (Y) of composite and $\mathrm{CaCO}_{3}$ particle loading level $(\mathrm{X})$ is shown below:

$$
Y=-12.9 X+15.75\left(R^{2}=0.99\right)
$$




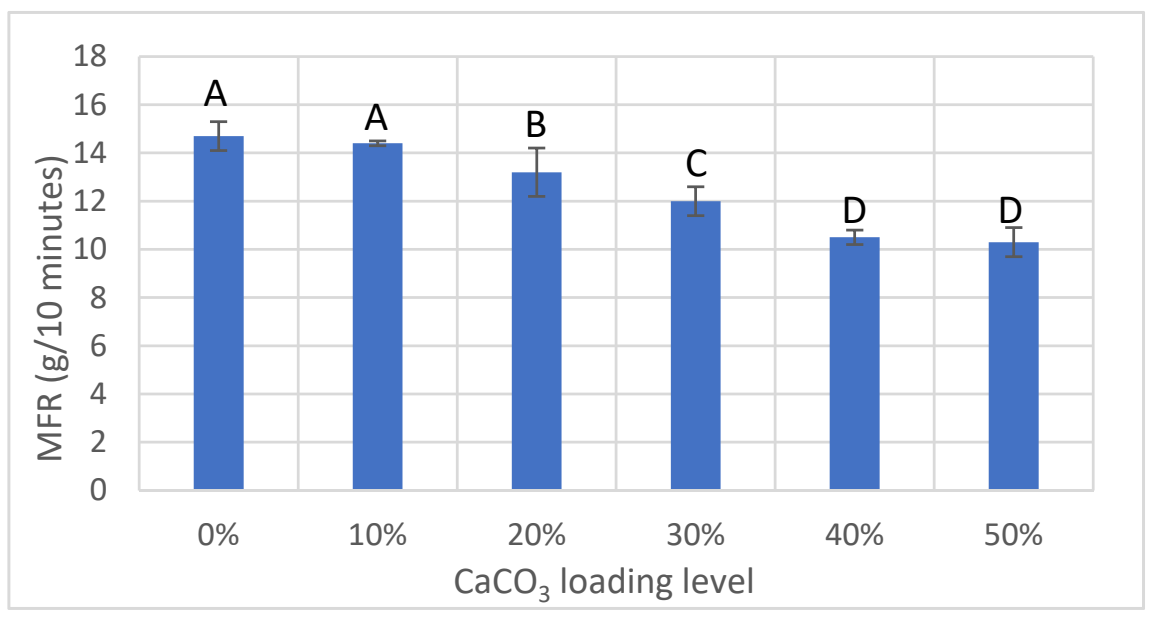

Figure 11. The MFR of $\mathrm{HPP}$ and $\mathrm{CaCO}_{3}$ particles filled HPP. The letters $\mathrm{A}, \mathrm{B}, \mathrm{C}$, and D represent the significant levels in statistical analysis. The values with different letters are significantly different.

When the $\mathrm{CaCO}_{3}$ particle loading level increased from 40 to $50 \mathrm{wt} . \%$, the MFR stay at the same level (Figure 11). At the $40 \mathrm{wt} . \%$ loading level, the flow of the polymer phase is mainly restricted by the $\mathrm{CaCO}_{3}$ particles and the effect of the $\mathrm{CaCO}_{3}$ particles on melt flow dominates the composite behaviors. Large amount of $\mathrm{CaCO}_{3}$ particles was identified in the SEM micrographs (Figure 9e,f) which showed the dispersion of $\mathrm{CaCO}_{3}$ particles at $40 \mathrm{wt} . \%$ loading in HPP. Additional $10 \mathrm{wt} . \% \mathrm{CaCO}_{3}$ particles did not change the composite MFR significantly.

\section{Conclusions}

At different loading levels, $\mathrm{CaCO}_{3}$ particles were mixed with a grade of HPP for manufacturing composites using an injection molding process. The mechanical behaviors of the composites were studied and analyzed in detail. The results indicated that tensile strengths decreased significantly with increasing loading levels of $\mathrm{CaCO}_{3}$ particles while the tensile and flexural moduli increased significantly with increasing filler loadings. Adding rigid $\mathrm{CaCO}_{3}$ particles changed the elastic deformation behaviors of the manufactured composites, resulting in higher moduli during tensile and flexural tests. The composite tensile properties changed linearly with increasing $\mathrm{CaCO}_{3}$ loadings. The mechanisms of changing $\mathrm{HPP}$ properties by including $\mathrm{CaCO}_{3}$ particles at different loadings were proposed for the tensile properties. The tensile strengths of the composites were mainly determined by the yielding strength of the polymer phase in the composites and the composite tensile strengths decreased linearly with the replacement of polymer phase in a linear relationship using 10, 20, 30, 40, and $50 \mathrm{wt} . \%$ of $\mathrm{CaCO}_{3}$ particles. The tensile strains at yielding also decreased linearly with increasing $\mathrm{CaCO}_{3}$ particles loading levels.

The notched Izod impact strength of the HPP was sustained by adding $\mathrm{CaCO}_{3}$ particles up to $40 \mathrm{wt} . \%$ while the unnotched impact strength decreased significantly with the addition of $\mathrm{CaCO}_{3}$ particles. Different deformation mechanisms during notched (fracture propagation) and unnotched (fracture initiation and propagation) impact tests were proposed to be the reason causing the different impact strengths. When $\mathrm{CaCO}_{3}$ particles were added into the composites, a different fracture surface was created during the Izod impact tests. During the notched Izod impact test, fracture propagated through a tortuous pathway along the interface between $\mathrm{HPP}$ and $\mathrm{CaCO}_{3}$ particles. The energy consumed for creating the rough surface of the composite can compensate the energy absorption capability loss of the polymer phase which was replaced by $\mathrm{CaCO}_{3}$ particles in the composites. The notched Izod impact strength of HPP can, therefore, be sustained with a loading level of $\mathrm{CaCO}_{3}$ particles up to $40 \mathrm{wt}$.\%. For unnotched Izod impact tests, addition of $\mathrm{CaCO}_{3}$ particles significantly lowered the energy needed for fracture initiation due to the incompatibility between $\mathrm{HPP}$ and $\mathrm{CaCO}_{3}$ particles. The fracture initiation dominantly 
determined the impact strength of the composite for unnotched Izod impact tests and significantly lower unnotched impact strengths were obtained with increasing loading levels of $\mathrm{CaCO}_{3}$ particles.

Author Contributions: Conceptualization, Y.P.; methodology, Y.P., X.W. and M.M.; validation, M.M. and Y.P.; formal analysis, Y.P. and M.M.; investigation, M.M. and Y.P.; resources, Y.P. and B.V.; data curation, M.M. and Y.P.; writing-original draft preparation, Y.P. and M.M.; writing—review and editing, Y.P. and B.V.; visualization, Y.P.; supervision, Y.P.; project administration, Y.P.; funding acquisition, Y.P. All authors have read and agreed to the published version of the manuscript.

Funding: This research was funded by the USDA National Institute of Food and Agriculture and by the Alabama Agricultural Experiment Station.

Conflicts of Interest: The authors declare no conflict of interest. The funders had no role in the design of the study; in the collection, analyses, or interpretation of data; in the writing of the manuscript, or in the decision to publish the results.

\section{References}

1. Shirvanimoghaddam, K.; Balaji, K.V.; Yadav, R.; Zabihi, O.; Ahmadi, M.; Adetunji, P.; Naebe, M. Balancing the toughness and strength in polypropylene composites. Compos. B-Eng. 2021, 223. [CrossRef]

2. Jancar, J.; Dianselmo, A.; Dibenedetto, A.T.; Kucera, J. Failure Mechanics in Elastomer Toughened Polypropylene. Polymer 1993, 34, 1684-1694. [CrossRef]

3. Eiras, D.; Pessan, L.A. Mechanical Properties of Polypropylene/Calcium Carbonate Nanocomposites. Mater. Res.-Ibero-Am. J. 2009, 12, 517-522. [CrossRef]

4. Deblieck, R.; Remerie, K.; Van den Fonteyne, W.; Boerakker, M. A Morphology-Based Model to Describe the Low-Temperature Impact Behaviour of Rubber-Toughened Polypropylene. Polymers 2021, 13, 2218. [CrossRef] [PubMed]

5. Maddah, H.A. Polypropylen as a promising plastic: A review. Am. J. Polym. Sci. 2016, 6, 1-11. [CrossRef]

6. Goldman, A.Y.; Copsey, C.J. Polypropylene toughened with calcium carbonate mineral filler. Mater. Res. Innov. 2000, 3, 302-307. [CrossRef]

7. Chan, C.M.; Wu, J.S.; Li, J.X.; Cheung, Y.K. Polypropylene/calcium carbonate nanocomposites. Polymer 2002, 43, $2981-2992$. [CrossRef]

8. Chafidz, A.; Kaavessina, M.; Al-Zahrani, S.; Al-Otaibi, M.N. Rheological and mechanical properties of polypropylene/calcium carbonate nanocomposites prepared from masterbatch. J. Thermoplast. Compos. 2016, 29, 593-622. [CrossRef]

9. Liang, J.Z.; Li, R.K.Y. Rubber toughening in polypropylene: A review. J. Appl. Polym. Sci. 2000, 77, 409-417. [CrossRef]

10. Jang, B.Z. Rubber-Toughening in Polypropylene. J. Appl. Polym. Sci. 1985, 30, 2485-2504. [CrossRef]

11. Bucknall, C.B.; Page, C.J. Rubber-Toughening of Plastics Part 6 Effects of Rubber Particles on the Kinetics of Creep in Polypropylene. J. Mater. Sci 1982, 17, 808-816. [CrossRef]

12. Wang, X.; Hu, S.; Guo, Y.; Li, G.Q.; Xu, R.W. Toughened High-Flow Polypropylene with Polyolefin-Based Elastomers. Polymers 2019, 11, 1976. [CrossRef]

13. Lin, Y.; Chen, H.B.; Chan, C.M.; Wu, J.S. The toughening mechanism of polypropylene/calcium carbonate nanocomposites. Polymer 2010, 51, 3277-3284. [CrossRef]

14. Shi, L.; Xiao, J.M. The toughening mechanism of rubber particles in polypropylene composite. IOP Conf. Ser.-Mat. Sci 2017, 164. [CrossRef]

15. Zuiderduin, W.C.J.; Westzaan, C.; Huetink, J.; Gaymans, R.J. Toughening of polypropylene with calcium carbonate particles. Polymer 2003, 44, 261-275. [CrossRef]

16. Chen, F.; Shangguan, Y.G.; Jiang, Y.S.; Qiu, B.W.; Luo, G.H.; Zheng, Q. Toughening with little rigidity loss and mechanism for modified polypropylene by polymer particles with core-shell structure. Polymer 2015, 65, 81-92. [CrossRef]

17. Zhang, L.; Li, C.Z.; Huang, R. Toughness mechanism in polypropylene composites: Polypropylene toughened with elastomer and calcium carbonate. J. Polym. Sci. Pol. Phys. 2004, 42, 1656-1662. [CrossRef]

18. Bartczak, Z.; Argon, A.S.; Cohen, R.E.; Weinberg, M. Toughness mechanism in semi-crystalline polymer blends: II. High-density polyethylene toughened with calcium carbonate filler particles. Polymer 1999, 40, 2347-2365. [CrossRef]

19. Fu, S.Y.; Feng, X.Q.; Lauke, B.; Mai, Y.W. Effects of particle size, particle/matrix interface adhesion and particle loading on mechanical properties of particulate-polymer composites. Compos. B-Eng. 2008, 39, 933-961. [CrossRef]

20. Zebarjad, S.M.; Tahani, M.; Sajjadi, S.A. Influence of filler particles on deformation and fracture mechanism of isotactic polypropylene. J. Mater. Process Tech. 2004, 155, 1459-1464. [CrossRef]

21. Badran, B.M.; Galeski, A.; Kryszewski, M. High-Density Polyethylene Filled with Modified Chalk. J. Appl. Polym. Sci. 1982, 27, 3669-3681. [CrossRef]

22. Liu, Z.H.; Kwok, K.W.; Li, R.K.Y.; Choy, C.L. Effects of coupling agent and morphology on the impact strength of high density polyethylene $/ \mathrm{CaCO}_{3}$ composites. Polymer 2002, 43, 2501-2506. [CrossRef] 
23. Wang, Y.; Lu, J.; Wang, G.H. Toughening and reinforcement of $\mathrm{HDPE} / \mathrm{CaCO}_{3}$ blends by interfacial modification interfacial interaction. J. Appl. Polym. Sci. 1997, 64, 1275-1281. [CrossRef]

24. Yue, C.Y.; Cheung, W.L. Discriminating between Strength-Based and Fracture-Based Approaches in Debonding in Glass FiberReinforced Polypropylene Composite. J. Mater. Sci. Lett. 1991, 10, 1335-1337. [CrossRef]

25. Ramsteiner, F.; Theysohn, R. On the Tensile Behavior of Filled Composites. Composites 1984, 15, 121-128. [CrossRef]

26. Kim, G.M.; Michler, G.H. Micromechanical deformation processes in toughened and particle filled semicrystalline polymers. Part 2: Model representation for micromechanical deformation processes. Polymer 1998, 39, 5699-5703. [CrossRef]

27. Kim, G.M.; Michler, G.H. Micromechanical deformation processes in toughened and particle-filled semicrystalline polymers: Part 1. Characterization of deformation processes in dependence on phase morphology. Polymer 1998, 39, 5689-5697. [CrossRef]

28. Thio, Y.S.; Argon, A.S.; Cohen, R.E.; Weinberg, M. Toughening of isotactic polypropylene with CaCO 3 particles. Polymer 2002, 43, 3661-3674. [CrossRef]

29. Zhang, Q.X.; Yu, Z.Z.; Xie, X.L.; Mai, Y.W. Crystallization and impact energy of polypropylene/CaCO 3 nanocomposites with nonionic modifier. Polymer 2004, 45, 5985-5994. [CrossRef]

30. Chen, N.; Wan, C.Y.; Zhang, Y.; Zhang, Y.X. Effect of nano-CaCO $\mathrm{Ca}_{3}$ on mechanical properties of PVC and PVC/blendex blend. Polym. Test. 2004, 23, 169-174. [CrossRef]

31. Allard, R.C.; Vukhanh, T.; Chalifoux, J.P. Fatigue Crack-Propagation in Mica-Filled Polyolefins. Polym Compos. 1989, 10, 62-68. [CrossRef]

32. Yang, K.; Yang, Q.; Li, G.X.; Sun, Y.J.; Feng, D.C. Morphology and mechanical properties of polypropylene/calcium carbonate nanocomposites. Mater. Lett. 2006, 60, 805-809. [CrossRef]

33. Maiti, S.N.; Mahapatro, P.K. Mechanical-Properties of i-PP/CaCO 3 Composites. J. Appl. Polym. Sci. 1991, 42, 3101-3110. [CrossRef]

34. Peng, Y.C.; Gallegos, S.A.; Gardner, D.J.; Han, Y.; Cai, Z.Y. Maleic anhydride polypropylene modified cellulose nanofibril polypropylene nanocomposites with enhanced impact strength. Polym. Compos. 2016, 37, 782-793. [CrossRef]

35. Jam, N.J.; Behravesh, A.H. Flow Behavior of HDPE-Fine wood particles composites. J. Thermoplast. Compos. 2007, $20,439-451$. [CrossRef]

36. Shumigin, D.; Tarasova, E.; Krumme, A.; Meier, P. Rheological and Mechanical Properties of Poly(lactic) Acid/Cellulose and LDPE/Cellulose Composites. Mater. Sci. 2011, 17, 32-37. [CrossRef] 